\title{
Running is the neurogenic and neurotrophic stimulus in environmental enrichment
}

\author{
Tali Kobilo, ${ }^{1}$ Qing-Rong Liu, ${ }^{2}$ Kriti Gandhi, ${ }^{1}$ Mohammed Mughal, ${ }^{3}$ Yavin Shaham, ${ }^{2}$ \\ and Henriette van Praag ${ }^{1,4}$ \\ ${ }^{1}$ Neuroplasticity and Behavior Unit, Laboratory of Neurosciences, Intramural Research Program, National Institute on Aging, \\ Baltimore, Maryland 21224, USA; ${ }^{2}$ Behavioral Neuroscience Branch, Intramural Research Program, National Institute on Drug Abuse, \\ Baltimore, Maryland 21224, USA; ${ }^{3}$ Cellular and Molecular Neuroscience Section, Laboratory of Neurosciences, National Institute \\ on Aging, National Institutes of Health, Baltimore, Maryland 21224, USA
}

\begin{abstract}
Environmental enrichment (EE) increases dentate gyrus (DG) neurogenesis and brain-derived neurotrophic factor (BDNF) levels. However, running is considered an element of EE. To dissociate effects of physical activity and enrichment on hippocampal neurogenesis and BDNF levels, young female C57BI/ 6 mice were housed under control, running, enrichment, or enrichment plus running conditions, and injected with bromodeoxyuridine. Cell genesis was assessed after $12 \mathrm{~d}$ and differentiation was analyzed 1 mo later. In addition, locomotor activity in the open field and hippocampal mature BDNF peptide levels were measured. Open-field adaptation was improved in all groups, compared to controls, but more so with running. New cell proliferation, survival, neuron number, and neurotrophin levels were enhanced only when running was accessible. We conclude that exercise is the critical factor mediating increased BDNF levels and adult hippocampal neurogenesis.
\end{abstract}

[Supplemental material is available for this article.]

Exposure to environmental enrichment (EE) has positive effects on brain function, including increased numbers of dendritic branches and spines, enlargement of synapses, and improved cognition (Bennett et al. 1964; Rosenzweig and Bennett 1996). More recently, it was discovered that EE enhances the survival of newly born neurons in the dentate gyrus (DG) of the hippocampus (Kempermann et al. 1997) and increases brain-derived neurotrophic factor (BDNF) levels (Falkenberg et al. 1992; Rossi et al. 2006; Sun et al. 2010). EE has many aspects, including increased opportunity for learning, socialization, and physical activity. Among these, exercise was found to enhance neurogenesis (van Praag et al. 1999). Subsequently, physical activity and enrichment have been regarded as equivalent neurogenic stimuli, albeit with different underlying mechanisms. Exercise is considered to mainly enhance cell proliferation, whereas enrichment is deemed to increase new cell survival (Olson et al. 2006; Kempermann et al. 2010). However, in many studies the enriched environment includes physical activity (Kempermann et al. 1997, 1998; van Praag et al. 1999; Rossi et al. 2006; Schloesser et al. 2010; Sun et al. 2010), making it difficult to assess the unique contributions of EE and exercise to adult neurogenesis, neurotrophin levels, and behavior.

The current study aims to directly differentiate between the effects of enriched environment only (EEO), physical activity (RUN), and the combination of enrichment and running (EER). Here we show that running is the critical factor in stimulating adult hippocampal neurogenesis and enhancing mature BDNF peptide levels. Moreover, enrichment in the absence of running does not increase adult hippocampal neurogenesis or BDNF levels in the hippocampus. Open-field adaptation was improved in all

${ }^{4}$ Corresponding author.

E-mail vanpraagh@mail.nih.gov.

Article is online at http://www.learnmem.org/cgi/doi/10.1101//m.2283011. groups as compared to controls, but more so in the groups that included running. These findings suggest that enrichment and exercise are distinct functional interventions.

Forty female C57B1/ 6 mice (5 wk old) were divided into four groups $(n=10)$ in same-size cages $\left(30^{\prime \prime} \times 33^{\prime \prime} \times 8^{\prime \prime}\right)$ : $(1)$ controls, CON; (2) runners RUN (10 running wheels, which allows all animals to run simultaneously); (3) enriched only, EEO; (4) enriched with running, EER. Enrichment, as shown in Figure 1, consisted of rearrangeable sets of tunnels, wood chunks, igloos, crawl balls, and huts which mice could climb on (Bio-Serve). The enrichment devices were rearranged every other week. All mice had unlimited access to water and standard rodent food. During the first $12 \mathrm{~d}$ of the study, the mice received daily single doses of bromodeoxyuridine (BrdU, $50 \mu \mathrm{g} / \mathrm{g}$ body weight, intraperitoneal). On day 13, a subset of mice ( $n=5$ from each group) was sacrificed to assay cell proliferation. The remaining mice continued to live in their respective experimental conditions for a total of $30 \mathrm{~d}$, until day 43 to measure cell survival and differentiation. Mice were deeply anaesthetized with isofluorane and perfused transcardially with $0.9 \%$ saline followed by $4 \%$ paraformaldehyde (PFA) in 0.1 M phosphate buffer, pH 7.4. Brains were post-fixed in 4\% PFA for $3 \mathrm{~d}$, followed by equilibration in $30 \%$ (wt/vol) sucrose. The brains were cut coronally $(40 \mu \mathrm{m})$ on a sliding freezing microtome (HM450, ThermoFisher). Sections were stored at $-20^{\circ} \mathrm{C}$ in a cryoprotectant solution.

An additional set of 48 female C57Bl/6 mice was tested in open-field behavior and used to quantify mature BDNF peptide levels in the hippocampus. These mice were housed under the same conditions (CON, RUN, EEO, EER; $n=12$ per group) for 43 d. On day 30 , mice were tested in an open-field arena $(27.3 \times$ $27.3 \mathrm{~cm}$, height $20.3 \mathrm{~cm}$ ) (Med Associates Inc.). Animals were placed in the center of the arena at the beginning of the testing procedure and were left undisturbed for $20 \mathrm{~min}$. The total distance traveled in the open field over $20 \mathrm{~min}$ was recorded 

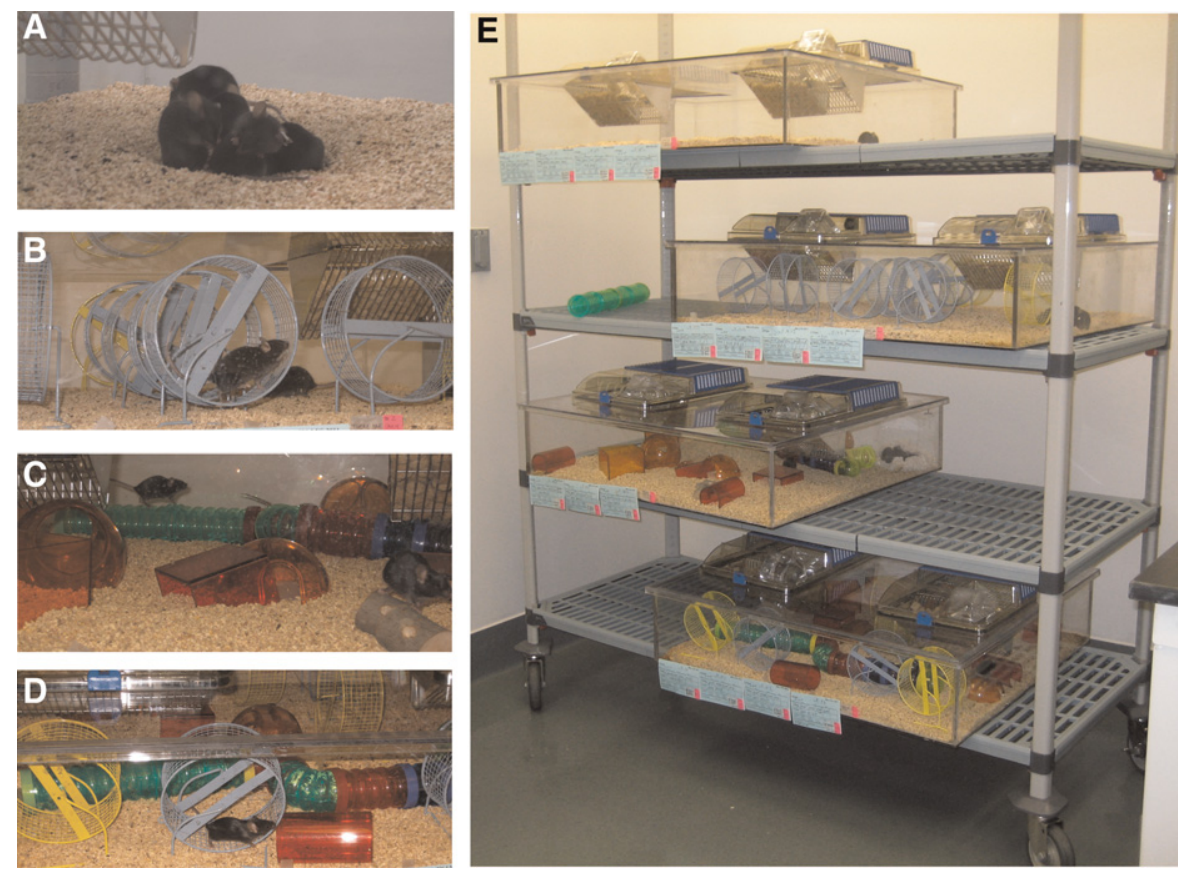

Figure 1. Housing of the experimental animals. Female $\mathrm{C} 57 \mathrm{BI} / 6$ mice $(n=10$ per group) were housed in large cages $\left(30^{\prime \prime} \times 33^{\prime \prime} \times 8^{\prime \prime}\right)$ as shown. $(A)$ Control (CON). (B) Running (RUN); cage with 10 running wheels for voluntary physical activity. (C) Enriched environment only (EEO). (D) Enrichment and running (EER); the cage contained enrichment objects similar to $C$, as well as 10 running wheels. $(E)$ Overview of the experimental cages.

and analyzed. Mice were perfused with $0.9 \%$ saline, and brain tissue was quickly removed, the hippocampus dissected and frozen on dry ice. Tissue was stored at $-80^{\circ} \mathrm{C}$ for later protein extraction to quantify mature BDNF peptide levels in the hippocampus.

Immunohistochemistry for BrdU and immunofluorescent double-labeling for BrdU and NeuN were performed on freefloating $40-\mu \mathrm{m}$ coronal sections that were pretreated for BrdU immunohistochemistry by denaturing DNA. The antibodies used were rat anti-BrdU (1:100; Accurate Chemical) and mouse anti-NeuN (1:100, Millipore). The fluorescent secondary antibodies used were donkey anti-mouse Cy3 (1:250, Jackson ImmunoResearch) and anti-rat Alexa-Fluor 488 (1:250, Invitrogen). BrdU-positive cell number and phenotype were analyzed as described previously (Creer et al. 2010). To determine the number of BrdU-labeled cells, a 1:6 series of equidistant sections (240 $\mu \mathrm{m}$ apart) was stained for BrdU using the peroxidase method (ABC system, with biotinylated donkey anti-mouse antibodies and diaminobenzidine as a chromogen, Vector Laboratories). A 1-in- 6 series of adjacent sections was stained with DAPI $(1 \mu \mathrm{L}$ per $10 \mathrm{~mL}$ of Tris-buffered saline [TBS] for $10 \mathrm{~min}$ ) to visualize nuclei and to measure granule cell layer volume. BrdU-positive cells were counted in a 1-in-6 series of five sections starting from the rostral dentate gyrus $(240 \mu \mathrm{m}$ apart $)$ through a $20 \times$ objective (BX51, Olympus) using the fractionator (counting frame, $35 \times$ $35 \mu \mathrm{m}$, grid size $55 \times 55 \mu \mathrm{m}$ ) system StereoInvestigator (MicroBrightfield Inc.). The number of BrdU-positive cells was then related to granule cell layer sectional volume to estimate total number of BrdU-positive cells per section. The granule cell volume was determined by summing the traced granule cell areas for each section multiplied by the distance between the five sections sampled. To analyze the phenotype of the newly born cells, a 1-in-12 series of sections $(480 \mu \mathrm{m}$ apart) was doublelabeled with BrdU and NeuN, and 50 BrdU-positive cells per mouse were analyzed by confocal microscopy (Olympus IX81 spinning disk confocal) and imaging software (Slidebook, Intelligent Imaging Innovations, Inc.). The ratio of BrdUpositive cells colabeling with NeuN was determined.

To assay mature BDNF peptide levels, hippocampal tissue was homogenized in $500 \mu \mathrm{L}$ of the $1 \times$ RIPA buffer containing protease inhibitors (Complete Mini, Roche Diagnostics) using pestles and microtubes (ISC BioExpress) and then sonicated with four pulses of $10 \mathrm{sec}$ at scale 4 (Ultrosonic Processor, Model GE70) at room temperature. The lysed samples were centrifuged at room temperature for $10 \mathrm{~min}$, and the supernatants were transferred to fresh tubes. The lysates were reduced with $100 \mathrm{mM}$ DTT at $70^{\circ} \mathrm{C}$ for $1 \mathrm{~h}$ to break strong disulfide bonds of BDNF. The protein concentrations were measured using the Bradford method (Bio-Rad). The samples were diluted to a final concentration of $3 \mu \mathrm{g} / \mu \mathrm{L}$ with the lysis buffer and $4 \times$ LDS NuPAGE sample buffer (Invitrogen). Before electrophoresis, the samples were heated at $90^{\circ} \mathrm{C}$ for $5 \mathrm{~min}$ and equilibrated to room temperature. Equal amounts of $15 \mu \mathrm{g}$ of the proteins were loaded onto $4 \%-12 \%$ gradient NuPAGE neutral polyacrylamide gel. The electrophoresis was carried out in $1 \times$ MES buffer, and the proteins in the gel were transferred to Immobilon-FL membrane (Millipore) using NuPAGE transfer buffer, according to the manufacturer's protocol (Invitrogen). The polyclonal rabbit antibody of BDNF (Santa Cruz Biotechnology, Inc., Cat\# sc-546) and the infrared-labeled goat against rabbit secondary antibodies (Li-Cor Biosciences) were used for immunostaining, according to Li-Cor's protocol. The specificity of BDNF antibody staining was confirmed by comigration with the reduced human recombinant BDNF $(0.1 \mu \mathrm{g})$ monomer (Neuromics, Cat\# PR15020) and by negative controls of other BDNF gene family members of NT- 4 NT- 3 and $\beta$-NGF $(0.1 \mu \mathrm{g}$ of each) recombinant proteins (R\&D, Cat\# 256-GF-100, 267-N3-005, and 268-N4-005, respectively) that did not show any signal (Supplemental Fig. S1). The positive control of human recombinant BDNF was applied to the same gel with the hippocampus samples. After the staining, the membranes were scanned by Li-Cor Odyssey Scanner and the integrated intensities of protein bands of BDNF were normalized with those of $\beta$-tubulin. The data are expressed as mean values \pm SEM. Statistical analysis was performed using two-way analysis of variance (ANOVA) and Fisher's post-hoc comparisons (StatView).

Subgranular progenitor cell proliferation in the DG was quantified $1 \mathrm{~d}$ (day 13) after the last BrdU injection in a subset of mice ( $n=5$ per group). Two-way ANOVA (running $\times$ housing) revealed a significant main effect of running $\left(F_{(1,16)}=22.43 ; P<\right.$ $0.0002)$. There was no main effect of housing $(P>0.53)$ and no interaction between running and housing $(P>0.93)$. Specific comparisons revealed that both RUN and EER had more cell proliferation than EEO and CON mice $(P<0.01)$ (Fig. 2; Table 1). The remaining mice were kept in their respective housing conditions for $4 \mathrm{wk}$ after the last BrdU injection to evaluate new cell survival and differentiation. There was a significant main effect of running for survival of BrdU-positive cells $\left(F_{(1,16)}=142.9 ; P<0.0001\right)$, but not of housing $(P>0.23)$, and no interaction between the two 

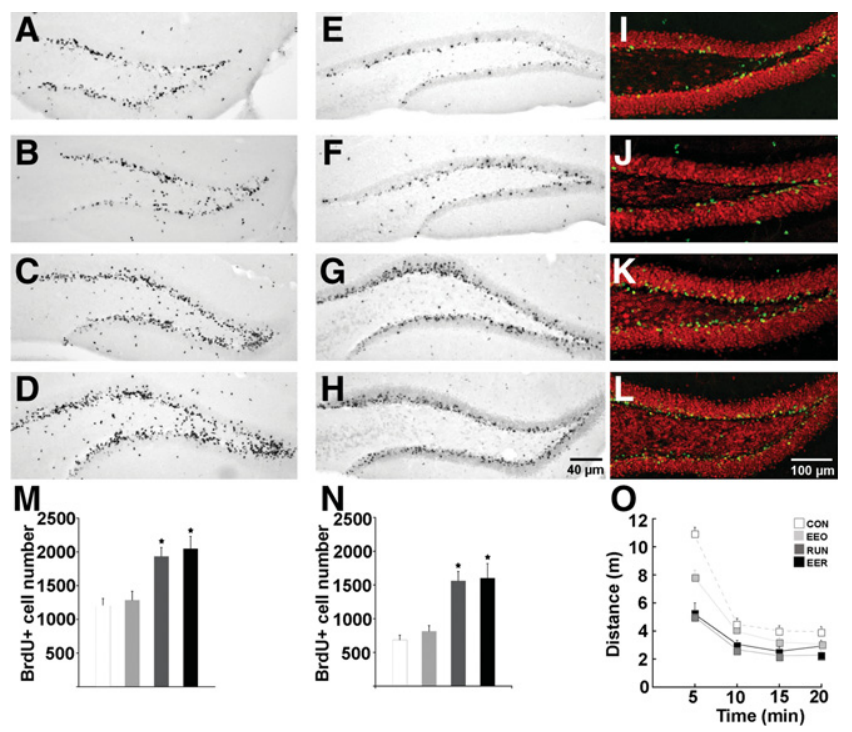

Figure 2. Dentate gyrus cell proliferation and neurogenesis, and openfield locomotion. Photomicrographs $(A-L)$ and quantification $(M, N)$ of BrdU-positive cells $1 \mathrm{~d}(A-D, M)$ and $4 \mathrm{wk}(E-H, N)$ after the last BrdU injection in $\operatorname{CON}(A, E, I)$, EEO $(B, F, J)$, RUN $(C, G, K)$, and $\operatorname{EER}(D, H, L)$ mice. $(I-L)$ Confocal images of BrdU-positive cells in CON $(I)$, EEO $(I)$, RUN $(K)$, and EER $(L) 4$ wk after the last injection. Sections were immunofluorescent double-labeled for BrdU (green) and NeuN (red) indicating neuronal phenotype. $(O)$ Open-field behavior was evaluated on day 30 . RUN and EER groups habituated more rapidly to the open field than CON and EEO $(P<0.04)$. EEO differed significantly from $\operatorname{CON}(P<0.01)$.

variables $(P>0.54)$. The number of cells was significantly greater in groups that contained the running wheels (RUN and EER) than in groups without the wheels (CON and EEO) $(P<0.01)$. There were no differences between CON and EEO $(P>0.21)$ or RUN and EER $(P>0.62)$ groups in cell proliferation and survival (Fig. 2; Table 1).

Differentiation of the surviving BrdU-positive cells was examined $4 \mathrm{wk}$ after the last injection by double-labeling for BrdU and NeuN. There was a significant main effect of running in the percentage of neuronal differentiation $\left(F_{(1,16)}=6.7 ; P<\right.$ 0.02) (Table 1), similar to previous research (van Praag et al. 1999). In addition, the number of new neurons was greater in the RUN and EER groups than in EEO and CON mice $\left(F_{(1,16)}=\right.$ 136.4; $P<0.0001$ ) (Table 1). The volume of the granule cell layer was increased in the groups including running $\left(F_{(1,16)}=8.6 ; P<\right.$ 0.009) (Table 1).

An additional set of mice was tested in the open field (CON, $n=12$; EEO, $n=11$; RUN, $n=12$; EER, $n=12) 30 \mathrm{~d}$ after assignment to their respective conditions. All groups habituated to the open-field environment as reflected by a gradual decrease in locomotor activity over $20 \min \left(F_{(3,43)}=161.6 ; P<0.0001\right)$. In addition, there was a significant interaction between distance traveled over time, running, and housing $\left(F_{(3,43)}=2.7 ; P<0.05\right)$ (Fig. 2). Specific comparisons showed that the RUN and EER groups traveled a shorter distance in the open field than CON and EEO $(P<0.04)$ and that EEO also differed significantly from CON $(P<0.01)$. In a subset of these mice (CON, $n=9$; EEO, $n=$ 10; RUN, $n=10$; EER, $n=9$ ), hippocampal mature BDNF peptide levels were measured. There was a significant interaction between exercise and housing $\left(F_{(1,31)}=4.7 ; P<0.04\right)$ and a main effect of exercise $\left(F_{(1,31)}=25.9 ; P<0.0001\right)$ but not of housing $(P>0.79)$. The neurogenic effect of exercise is supported by increased hippocampal BDNF protein levels in the groups that had access to running wheels (Fig. 3A,B). The mature BDNF peptide (15 kD) levels increased in RUN and EER mice when compared to CON $(P<0.01)$ and EEO $(P<0.04)$ groups. Hippocampal BDNF levels did not differ between CON and EEO $(P>0.18)$ or between the RUN and EER $(P>0.10)$ groups.

Our experiments show that running increases neurogenesis and mature BDNF peptide levels in the hippocampus, while enrichment by itself does not have these effects. These results clearly point out that enrichment and running are distinct interventions for these parameters, as opposed to the general assumption that they are equivalent. Increased BDNF gene expression and protein levels as result of enrichment is often reported under conditions that include running wheels (Falkenberg et al. 1992; Rossi et al. 2006; Schloesser et al. 2010; Sun et al. 2010). In fact, these studies refer to EER conditions as enrichment. However, our data demonstrate that running is the critical element enhancing neurogenesis and mature BDNF peptide levels. Therefore, for these aspects, running and enrichment should be considered as separate conditions.

Previously, enrichment with a single running wheel per cage had either no effect on cell genesis (Kempermann et al. 1997; van Praag et al. 1999) or showed an increase (Kempermann et al. 1998) in a strain-dependent manner. Interestingly, enrichment designed to make physical activity (10 wheels) easily accessible to all mice in the cage enhances cell proliferation in female $\mathrm{C} 57 \mathrm{Bl} / 6$ mice. Indeed, in studies with a single running wheel in the enriched environment, the number of mice $(n=12-14)$ per cage was largest during the period of daily BrdU injections (Kempermann et al. 1997; van Praag et al. 1999), immediately after which five to six mice per group were removed. Thus, during the time when proliferation was measured, there was less opportunity for each mouse to utilize the wheel than during the subsequent 4-wk survival period. Furthermore, our results appear to contrast with results by other investigators that enrichment without running increases new cell survival and neurogenesis (Ehninger and Kempermann 2003; Fabel et al. 2009). However, in one study the neurogenic effects of enrichment only were smaller than running (Ehninger and Kempermann 2003). In addition, in a recent report, enrichment only showed a trend toward an increased neurogenesis as compared to control conditions but did not reach statistical significance (Fabel et al. 2009), a finding consistent with our present results. It should also be noted that in these studies, the mice in the control groups were housed in smaller cages than the enriched conditions, which may reduce activity levels. In the present study, the cages were sized identically for all four treatment groups.

Table 1. Proliferation and survival of BrdU-positive cells

\begin{tabular}{|c|c|c|c|c|}
\hline & CON & EEO & RUN & EER \\
\hline $\begin{array}{l}\text { Proliferation, } \\
\text { day } 1\end{array}$ & (122) & 145) & 47)* & $205)^{*}$ \\
\hline Survival, 4 wk & $686(35)$ & $815(42)$ & 1561 (69)* & 1603 (107)* \\
\hline $\begin{array}{l}\text { Phenotype } \\
\text { (\% neurons) }\end{array}$ & 86.3 & 86.2 & $92.8(2.4)^{*}$ & $91.7(2.1)^{*}$ \\
\hline New & & & $1449(80)^{*}$ & $1471(103)^{*}$ \\
\hline Volume & $0.17(0.006)$ & $0.17(0.005)$ & $0.23(0.01)$ & * $0.22(0.03)$ \\
\hline
\end{tabular}

Mice were assigned to control (CON), enriched (EEO), running (RUN), and combination of enrichment and running (EER) groups and received BrdU $(50 \mu \mathrm{g} / \mathrm{g})$ from day 1 to day 12 . Cell proliferation was assessed on day 13 ( $n=5$ per mice group; five sections per dentate gyrus), $1 \mathrm{~d}$ after the last injection. Survival of the BrdU-labeled cells and volume of the dentate gyrus were determined $4 \mathrm{wk}$ after the last BrdU injection. Phenotype of the surviving cells was determined by immunofluorescent double-labeling for BrdU and NeuN (neurons). The percentage of BrdU-positive cells double-labeled for NeuN and new neuron number is presented. All data are presented as means (standard error). (*) Significantly different from CON and EEO; $P<0.01$. 
A

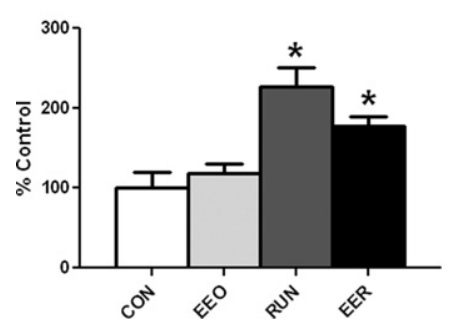

B

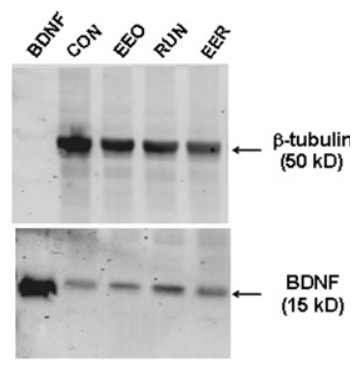

Figure 3. Hippocampal BDNF levels. (A) Mature BDNF peptide levels were significantly increased in the hippocampi of mice in the running (RUN, $n=8$ ) and enriched plus running (EER, $n=9)$ groups compared to the enriched only (EEO, $n=10$ ) and control (CON, $n=8$ ) groups. Specific comparisons showed that RUN, EER, and EEO groups differed $(P<0.04)$, as well as RUN, EER and CON groups $(P<0.01)$. (B) One replicate of the Western blot is shown for each condition, as well as recombinant mature human BDNF peptide as a positive control and $\beta$-tubulin as an endogenous control.

Additional support for the selective neurogenic effect of exercise comes from the finding in our study that mature BDNF peptide levels are only increased in the groups that included wheel running (RUN and EER). Our results are consistent with research by others showing that exercise has a strong effect on neurotrophin gene expression and protein levels, in particular in the hippocampus (Neeper et al. 1995; Cotman and Berchtold 2002; Chen and Russo-Neustadt 2009; Stranahan et al. 2009). Moreover, recent research showed that BDNF plays a role in cognitive effects of exercise in humans (Erickson et al. 2011) and is important for physical activity-induced neurogenesis in rodents (Li et al. 2008). Indeed, wheel running increased BDNF gene expression selectively in the dentate gyrus (Farmer et al. 2004). In addition, in mice lacking the receptor tyrosine kinase TrkB in hippocampal progenitor cells, no increase in proliferation or neurogenesis is observed in response to wheel running (Li et al. 2008). Similarly, in conditional BDNF knockout mice, the neurogenic response to exercise was impaired (Choi et al. 2009). While the underlying cellular mechanisms remain unclear, it has been suggested that running wheel exercise may activate NMDA receptors in the hippocampus and that in turn may enhance mature BDNF production and secretion. Indeed, the running-induced enhancement of BDNF levels and hippocampal neurogenesis is suppressed in mice lacking the NMDA receptor $\varepsilon 1$ (Kitamura et al. 2003).

Although our research shows that running is the main neurogenic and neurotrophic factor, it should be noted that enrichment has cellular and behavioral benefits in the absence of running. In our study, the two groups that included running (RUN and EER) showed the greatest habituation to the open field. However, enrichment only (EEO) mice adapted better than controls. Reduced locomotor activity in a novel environment over time in the open field may reflect improved information processing and reduced emotionality associated with enrichment (Crawley et al. 1997). In rats, enrichment without wheel running has been shown to have anxiolytic effects upon exposure to an inescapable foot shock procedure and result in altered monoamine metabolism (Hendriksen et al. 2010). Enrichment only also has effects on synaptic plasticity, such as increased dendritic complexity of young granule neurons (Beauquis et al. 2010), enhanced arborization of cortical neurons (Ip et al. 2002), and elevated synaptophysin levels in hippocampus and cortex (Lambert et al. 2005). Thus, environmental enrichment and physical activity share common features pertaining to synaptic plasticity (van

Praag et al. 2000; Will et al. 2004). Unique to exercise is the enhancement of BDNF levels and adult neurogenesis in the hippocampus.

\section{Acknowledgments}

This research was supported by the Intramural Research Program of the NIH of the National Institute on Aging (NIA) and National Institute on Drug Abuse (NIDA), NIH. We thank Linda R. Kitabayashi for expert assistance with preparation of the figures. We thank Mike Still for animal care and technical assistance.

\section{References}

Beauquis J, Roig P, De Nicola AF, Saravia F. 2010. Short-term environmental enrichment enhances adult neurogenesis, vascular network and dendritic complexity in the hippocampus of Type 1 diabetic mice. PLoS One 5: e13993. doi: 10.1371/journal.pone.0013993.

Bennett EL, Diamond MC, Krech D, Rosenzweig MR. 1964. Chemical and anatomical plasticity brain. Science 30: 610-619.

Chen MJ, Russo-Neustadt AA. 2009. Running exercise-induced up-regulation of hippocampal brain-derived neurotrophic factor is CREB-dependent. Hippocampus 19: 962-972.

Choi SH, Li Y, Parada LF, Sisodia SS. 2009. Regulation of hippocampal progenitor cell survival, proliferation and dendritic development by BDNF. Mol Neurodegener 4: 52. doi: 10.1186/1750-1326-4-52.

Cotman CW, Berchtold NC. 2002. Exercise: A behavioral intervention to enhance brain health and plasticity. Trends Neurosci 25: 295-301.

Crawley JN, Belknap JK, Collins A, Crabbe JC, Frankel W, Henderson N, Hitzemann RJ, Maxson SC, Miner LL, Silva AJ, et al. 1997. Behavioral phenotypes of inbred strains of mice. Psychopharmacology 132: $107-124$.

Creer DJ, Romberg C, Saksida LM, van Praag H, Bussey TJ. 2010. Running enhances spatial pattern separation in mice. Proc Natl Acad Sci 107: $2367-2372$.

Ehninger D, Kempermann G. 2003. Regional effects of wheel running and environmental enrichment on cell genesis and microglia proliferation in the adult murine neocortex. Cereb Cortex 13: 845-851.

Erickson KI, Voss MW, Prakash RS, Basak C, Szabo A, Chaddock L, Kim JS, Heo S, Alves H, White SM, et al. 2011. Exercise training increases size of hippocampus and improves memory. Proc Natl Acad Sci 108: 3017-3022.

Fabel K, Wolf SA, Ehninger D, Babu H, Leal-Galicia P, Kempermann G. 2009. Additive effects of physical exercise and environmental enrichment on adult hippocampal neurogenesis in mice. Front Neurosci 3: 50 .

Falkenberg T, Mohammed AK, Henriksson B, Persson H, Winblad B, Lindefors N. 1992. Increased expression of brain-derived neurotrophic factor mRNA in rat hippocampus is associated with improved spatial memory and enriched environment. Neurosci Lett 13: 153-156.

Farmer J, Zhao X, van Praag H, Wodtke K, Gage FH, Christie BR. 2004. Effects of voluntary exercise on synaptic plasticity and gene expression in the dentate gyrus of adult male Sprague-Dawley rats in vivo. Neuroscience 124: 71-79.

Hendriksen H, Prins J, Olivier B, Oosting RS. 2010. Environmental enrichment induces behavioral recovery and enhanced hippocampal cell proliferation in an antidepressant-resistant animal model for PTSD. PLoS One 5: e11943. doi: 10.1371/journal.pone.0011943.

Ip EY, Giza CC, Griesbach GS, Hovda DA. 2002. Effects of enriched environment and fluid percussion injury on dendritic arborization within the cerebral cortex of the developing rat. J Neurotrauma 19: $573-585$.

Kempermann G, Kuhn HG, Gage FH. 1997. More hippocampal neurons in adult mice living in an enriched environment. Nature 386: 493-495.

Kempermann G, Brandon EP, Gage FH. 1998. Environmental stimulation of $129 /$ SvJ mice causes increased cell proliferation and neurogenesis in the adult dentate gyrus. Curr Biol 13: 939-942.

Kempermann G, Fabel K, Ehninger D, Babu H, Leal-Galicia P, Garthe A, Wolf SA. 2010. Why and how physical activity promotes experience-induced brain plasticity. Front Neurosci 4: 189.

Kitamura T, Mishina M, Sugiyama H. 2003. Enhancement of neurogenesis by running wheel exercises is suppressed in mice lacking NMDA receptor $\varepsilon 1$ subunit. Neurosci Res 47: 55-63.

Lambert TJ, Fernandez SM, Frick KM. 2005. Different types of environmental enrichment have discrepant effects on spatial memory and synaptophysin levels in female mice. Neurobiol Learn Mem 83: 206-216. 
Li Y, Luikart BW, Birnbaum S, Chen J, Kwon CH, Kernie SG, Bassel-Duby R, Parada LF. 2008. TrkB regulates hippocampal neurogenesis and governs sensitivity to antidepressive treatment. Neuron 59: 399-412.

Neeper SA, Gómez-Pinilla F, Choi J, Cotman C. 1995. Exercise and brain neurotrophins. Nature 373: 109.

Olson AK, Eadie BD, Ernst C, Christie BR. 2006. Environmental enrichment and voluntary exercise massively increase neurogenesis in the adult hippocampus via dissociable pathways. Hippocampus 16: 250-260.

Rosenzweig MR, Bennett EL. 1996. Psychobiology of plasticity: Effects of training and experience on brain and behavior. Behav Brain Res 78: $57-65$.

Rossi C, Angelucci A, Costantin L, Braschi C, Mazzantini M, Babbini F, Fabbri ME, Tessarollo L, Maffei L, Berardi N, et al. 2006. Brain-derived neurotrophic factor (BDNF) is required for the enhancement of hippocampal neurogenesis following environmental enrichment. Eur J Neurosci 24: 1850-1856.

Schloesser RJ, Lehmann M, Martinowich K, Manji HK, Herkenham M. 2010. Environmental enrichment requires adult neurogenesis to facilitate the recovery from psychosocial stress. Mol Psychiatry 15: $1152-1163$
Stranahan AM, Lee K, Martin B, Maudsley S, Golden E, Cutler RG, Mattson MP. 2009. Voluntary exercise and caloric restriction enhance hippocampal dendritic spine density and BDNF levels in diabetic mice. Hippocampus 19: 951-961.

Sun H, Zhang J, Zhang L, Liu H, Zhu H, Yang Y. 2010. Environmental enrichment influences BDNF and NR1 levels in the hippocampus and restores cognitive impairment in chronic cerebral hypoperfused rats. Curr Neurovasc Res 7: 268-280.

van Praag H, Kempermann G, Gage FH. 1999. Running increases cell proliferation and neurogenesis in the adult mouse dentate gyrus. Nat Neurosci 2: 266-270.

van Praag H, Kempermann G, Gage FH. 2000. Neural consequences of environmental enrichment. Nat Rev Neurosci 3: 191-198.

Will B, Galani R, Kelche C, Rosenzweig MR. 2004. Recovery from brain injury in animals: Relative efficacy of environmental enrichment, physical exercise or formal training (1990-2002). Prog Neurobiol 72: $167-182$

Received May 18, 2011; accepted in revised form July 18, 2011. 


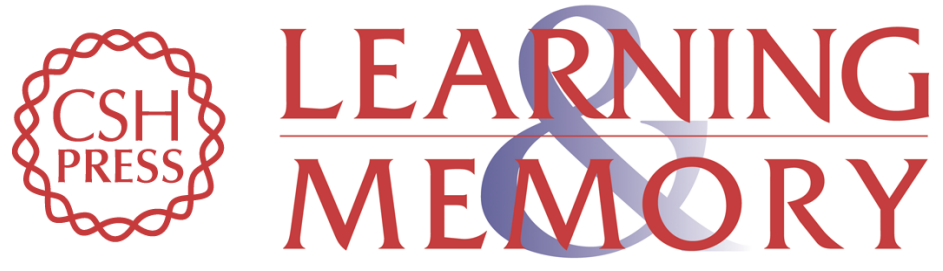

\section{Running is the neurogenic and neurotrophic stimulus in environmental enrichment}

Tali Kobilo, Qing-Rong Liu, Kriti Gandhi, et al.

Learn. Mem. 2011, 18:

Access the most recent version at doi:10.1101//m.2283011

Supplemental http://learnmem.cshlp.org/content/suppl/2011/08/30/18.9.605.DC1
Material

References This article cites 30 articles, 2 of which can be accessed free at: http://learnmem.cshlp.org/content/18/9/605.full.html\#ref-list-1

License

Email Alerting Receive free email alerts when new articles cite this article - sign up in the box at the Service top right corner of the article or click here. 